\title{
Taidehistorian ja kehitysmaatutkimuksen suhde poikkitieteellisenä haasteena
}

\section{Essi Lamberg}

doi.org/10.23995/tht.112172

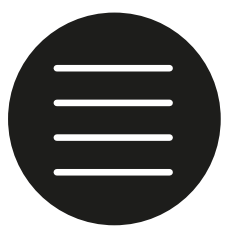

Kirjoituksessa tarkastellaan sitä, minkälaisia haasteita arkkitehtuurihistorian tutkimus niin kutsutuissa kehitysmaissa nostaa esiin ja minkälaisia valmiuksia ne taidehistorian tutkijalta edellyttävät. Keskeisimpänä tarkastelun kohteena on taidehistorian tieteenalan suhde kehitysmaatutkimukseen. Artikkeli perustuu kirjoittajan poikkitieteellisen, suomalaisten arkkitehtien liikkuvuutta Saharan eteläpuolisessa Afrikassa kehitysyhteistyön vaikutuspiirissä 1960-1980-luvuilla tarkastelevan väitöskirjahankkeen aikana muodostuneisiin tutkimustuloksiin ja havaintoihin. Kehitysyhteistyöhankkeisiin osallistuminen edellytti arkkitehdeilta uutta ammatillista aluevaltausta alakohtaisine tiedollisine ja kyvyllisine vaatimuksineen. Samalla tavalla alan tutkimus edellyttää tutkijalta muidenkin tieteenalojen kuin taidehistorian hallintaa. Se, miten tieteenalarajat ja niiden olemus mielletään, vaikuttaa oleellisesti siihen, miten luontevana tai epäluontevana taidehistorian ja kehitysmaatutkimuksen välinen suhde näyttäytyy.

Asiasanat: taidehistoria, kehitysmaatutkimus, kehitysyhteistyö, poikkitieteellisyys 
Kehitysyhteistyön piirissä syntyneiden aineistojen tutkimus taidehistorian teorioiden, metodien ja näkökulmien valossa herättää usein kummastusta. Kotimaisella tieteen kentällä taidehistoria ja kehitysmaatutkimus ${ }^{1}$ kohtaavat harvoin. Kansainvälisesti tilanne on toinen. Eurooppalaisissa yliopistoissa arkkitehtien osallisuutta kehitysyhteistyössä tutkivat henkilöt ovat usein itse taustaltaan arkkitehtejä ja työskentelevät teknisissä korkeakouluissa. Keskityn kuitenkin suomalaiseen kontekstiin ja siihen, minkälaisia kysymyksiä arkkitehtuurin historian suhteesta kehitysmaatutkimukseen ja kehitysyhteistyöhön herää juuri suomalaisen tieteen kentällä. Esitän, että se, miten tieteenalojen rajat ja niiden olemus mielletään, vaikuttaa oleellisesti siihen, miten luontevana tai epäluontevana taidehistorian ja kehitysmaatutkimuksen välinen suhde näyttäytyy.

Suomalaisten arkkitehtien työskentelyä kehitysyhteistyön palveluksessa tunnetaan toistaiseksi melko vähän. Tutkin väitöskirjassani sitä, miten suomalaisten arkkitehtien ja yhdyskuntasuunnittelijoiden ammattikunta integroitui asteittain osaksi Suomen ulkoministeriön harjoittamaa kehitysyhteistyötä 1960-luvulta 1980-luvulle. Kehitysyhteistyökontekstissa arkkitehdeista ja suunnittelijoista tuli eräänlaisia diplomaatteja, jotka edustivat ja edistivät Suomen valtion ulkopoliittisia intressejä. Samalla heidän ammatillinen toimialansa laajeni uusiin suuntiin, loi työpaikkoja ja mahdollisti entistä paremman kansainvälisen liikkuvuuden. Suomalaiset suunnittelualan ammattilaiset osallistuivat moninaisiin kehityshankkeisiin seutusuunnittelusta taloussuunnitteluun, yleiskaavasuunnitteluun ja asemakaavasuunnitteluun. Aihepiiri on vielä lähihistoriaa ja monilla arkkitehtuurin, suunnittelun ja rakentamisen parissa toimineilla on omakohtaisia kokemuksia ulkomaankomennuksista ulkoministeriön ja muiden työnantajien palveluksessa. Aiheen

$1 \quad$ Helsingin yliopiston kehitysmaatutkimuksen oppiaine vaihtoi nimensä hiljattain globaaliksi kehitystutkimukseksi. Käytän tässä tekstissä vielä vanhaa nimeä korostaakseni tieteenhistoriallista ulottuvuutta. tutkimuksella on käsiteltävänään lukuisia poikkitieteellisyyteen liittyviä haasteita.

Suomalaisessa taidehistoriassa kytkökset afrikkalaisiin taiteisiin, kieliin ja kulttuureihin ovat vähäisiä. Afrikkaa tai afrikkalaisuutta kuvaavia aiheita on eurooppalaisen taiteen historiassa lähestytty "toisina", "ulossuljettuina" ja "eivalkoisina". 2 Taidehistorian tieteenalan suhde afrikkalaisiin kulttuuriympäristöihin ja -perimään ei ole ongelmaton, kuten ei myöskään taidehistorian teorioiden ja menetelmien soveltaminen ratkaisukeskeiseen kehitysmaatutkimukseen ja kehitysyhteistyön piirissä syntyneisiin aineistoihin. Taidehistorian länsikeskeinen kaanon ja sen vaikea suhde länsimaiden ulkopuolisiin kulttuuripiireihin antaa oman värinsä myös arkkitehtuurin historian tutkimukselle. Viime vuosina arkkitehtien ja arkkitehtuurin transnationaalisen liikkuvuuden tutkimus on kokenut suoranaisen buumin ja tuonut enenevässä määrin esiin kolonialismin tai jälkikolonialismin geopoliittisia ilmentymiä rakennetussa ympäristössä. Vaikka työskentelyä kehitysyhteistyön parissa tunnetaan Suomessa huonosti, se on pysynyt ajankohtaisena osana suomalaisten arkkitehtien tehtäväkenttää nykypäiviin saakka.

Kehitysyhteistyön historialla ja taidehistorian tieteenalalla on enemmän yhteistä kuin voisi ensi alkuun olettaa. Viimeistään 1960-luvulla suomalaiset arkkitehdit liittyivät kansainväliseen arkkitehtien joukkoon, jonka tehtäväkentäksi muodostui Saharan eteläpuolisessa Afrikassa toisen maailmansodan jälkeen itsenäistyneiden

Albert Boime, The art of exclusion: Representing blacks in the nineteenth century (London: Thames \& Hudson, 1990); Blacks and blackness in European art of the long nineteenth century, eds. Adrienne L. Childs \& Susan Houghton Libby (Farnham Surrey, England; Burlington: Ashgate, 2014); Jan Nederveen Pieterse, White on black: Images of Africa and blacks in western popular culture (New Haven: Yale University Press, 1992). 


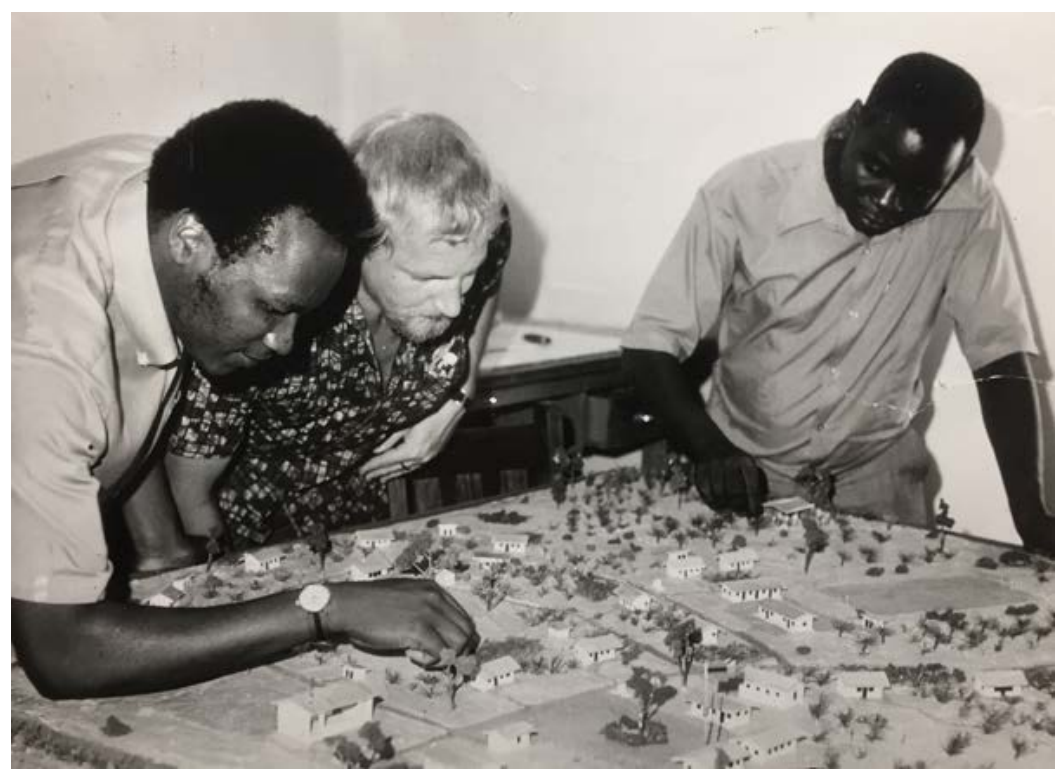

Kuva 1. Rakennusinsinööri Erkki Laitinen työskenteli Tansaniassa Suomen toisessa kehitysjoukossa vuosina 1970-1972. Kuvasta kerrotaan kansanedustaja Reino Breilinin kirjoittamassa artikkelissa sosiaalidemokraattisessa Eteenpäin-lehdessä 7.2.1973 seuraavaa: "Hänen toimipaikkansa oli maaseutukehityksen ministeriön piirustuskonttorissa, jossa hän suunnitteli rakennuksia ujamaa-kyliin ja maaseudun koulutuskeskuksiin. Vincent Paul Kyauka (vas.) ja Ahmed Mkallah toimivat hänen assistentteinaan. Kuvassa näkyy työryhmän itsenäisyyden kymmenvuotisjuhlia varten rakentama ujamaa-kylän pienoismalli. Kuva: Ulkoministeriön arkisto, kuva- ja lehtileikekokoelma, Helsinki / kuvaaja tuntematon.

maiden kansalliset kehitystavoitteet. ${ }^{3}$ Kansakuntien rakentaminen näkyi arkkitehtien työpöydillä lukuisina uusina julkisina rakennuksina, kuten kouluina, sairaaloina, maatalouskeskuksina, stadioneina, hotelleina, uusina asuinalueina ja pääkaupunkeina. ${ }^{4}$ 1970-luvulla suomalaiset arkkitehdit osallistuivat erilaisiin yhdyskuntasuunnitteluprojekteihin ympäri Afrikkaa, kes-

Essi Lamberg, "Development cooperation and national planning: analysing Finnish complicity in postcolonial Tanzania's decentralization reform and regional development," Planning Perspectives 36, no. 4 (2021): 689-717. DOI: 10.1080/02665433.2020.1851292.

Luce Beeckmans, “The Architecture of Nation-building in Africa as a Development Aid Project: Designing the capital cities of Kinshasa (Congo) and Dodoma (Tanzania) in the post-independence years," Progress in Planning 122 (2018): 1-28. DOI: 10.1016/j.progress.2017.02.001; Kim De Raedt, "Policies, people, projects. School building as development aid in postcolonial Sub-Saharan Africa," ABE journal 12 (2018); Łukasz Stanek, "Architects from Socialist Countries in Ghana (1957-67). Modern Architecture and Mondialisation," Journal of the Society of Architectural Historians 74, no. 4 (2015): 416-442. DOI: 10.1525/ jsah.2015.74.4.416; Inbal Ben-Asher Gitler, "Campus Architecture as Nation Building: Israeli architect Arieh Sharon's Obafemi Awolowo University Campus, IleIfe, Nigeria," in Third world modernism: Architecture, development and identity, eds. Duanfang Lu (London: Routledge, 2010), 113-140; Ray Bromley, "Towards Global Human Settlements: Constantinos Doxiadis as Entrepreneur, Coalition-builder and Visionary," in Urbanism: Imported or exported?: native aspirations and foreign plans, eds. Joe Nasr \& Mercedes Volait (London: Wiley-Academy, 2003), 316-340. keisimpinä yhteistyökumppanimaina Tansania ja Etiopia. Ratkaisevaa tämän kauden arkkitehtien työn kannalta oli osallisuus Suomen ulkoministeriön harjoittamassa kehitysyhteistyössä. ${ }^{5}$

Kehitysyhteistyöhankkeita tutkittaessa joutuu väistämättä osaksi neuvottelua siitä, mitä pidetään taidehistorian alalla sopivina tutkimuskohteina tai tutkimukseen sopivina aineistoina. Aineisto, jonka kautta suomalaisten arkkitehtien osallisuutta kehitysyhteistyössä voi tutkia, on muodostunut monitieteisesti. Hankkeissa toimineista suurin osa oli koulutukseltaan jotain muita kuin arkkitehteja tai yhdyskuntasuunnittelijoita. ${ }^{6}$ Laajat, alueellisia tai valtiollisia kehityshankkeita käsittelevät kehitysyhteistyöprojektit vaativat monenlaista osaamista ja on selvää, että suunnitteluviennin kaltaisissa asiayhteyksissä on mahdotonta erottaa tiettyä arkkitehtia kaikista niistä diplomaattien, virkamiesten, poliitikkojen, konsulttien, yritysten, ministeriöiden, kansainvälisten järjestöjen ja ulkovaltojen edus-

Essi Lamberg, "Development cooperation and national planning"; Juhani Koponen, Finnish Aid to Tanzania: Still Afloat (Helsinki: University of Helsinki, Institute of Development Studies, 2001).

6 Essi Lamberg, "Architects, Consulting Companies and Private Business Promotion in Development Cooperation: The Case of Finnplanco and Finnconsult in Tanzania, 1974-1975," Architectural Histories, (2021, tulossa). 
tajien verkostoista, joissa arkkitehdit toimivat ja joiden mahdollistamissa puitteissa he työskentelivät. Lisäksi arkkitehdin työhön vaikuttivat avun vastaanottajamaan valtiopäämiesten, hallitusten, parlamenttien ja virkamiesten asettamat määräykset, toiveet ja sisäpoliittiset tarpeet. Kehitysmaatutkimus on lähtökohtaisesti monitieteinen ala, jonka juuret ovat muun muassa antropologiassa, sosiologiassa, taloustieteessä ja politiikan tutkimuksessa. Samoin kehitysyhteistyön historian tutkija kohtaa väistämättä lukuisia eri tieteenaloja, joiden tontille tutkimuksen rihmat ulottuvat.

Tutkimukseni keskiöön kuuluvissa hankkeissa on työskennellyt arkkitehtien lisäksi muun muassa eri alojen insinöörejä, taloustieteilijöitä, agronomeja, väestötieteilijöitä, rakennusalan ammattilaisia ja politiikan tutkijoita. On selvää, että yksi tutkija ei voi saavuttaa ammattilaistason asiantuntemusta näillä kaikilla aloilla. On muistettava, että samalla tavalla kuin monitieteisyys asettaa haasteita nykytutkimukselle, ovat kehitysyhteistyön tekijät, mukaan lukien arkkitehdit, joutuneet kohtaamaan ne omassa työssään hankkeiden toteuttamisen aikana. Kun aineisto on lähtökohtaisesti monitieteistä, on tutkijan tehtävä ja keskeinen haaste miettiä, mitä annettavaa hänen oman tieteenalansa keskeisillä teoreettisilla tai metodisilla lähestymistavoilla voi tällaisen aineiston tutkimukselle olla.

Poikkitieteellisen projektityöskentelyn puitteissa syntyneen aineiston tutkimus edellyttää tutkijalta monien käytännöllisten haasteiden ylittämistä. Kansainvälisestikin katsoen kehitysyhteistyön piirissä tapahtunut suunnitteluyhteistyö on verrattain tuore tutkimuskohde, eikä esimerkiksi kattavia yleisesityksiä tai vakiintuneita diskurs- seja vielä juuri ole. ${ }^{7}$ Monet keskeisistä diskursseista rakentuvat arkkitehtuurin ja imperialismin välisten suhteiden tutkimuksen pohjalle, mikä aiheuttaa pohjoismaisten tapausesimerkkien tutkimukselle omat haasteensa. ${ }^{8}$ Useimmiten tutkimukselle relevanttia tutkimuskirjallisuutta, sikäli kun sitä on ylipäätään saatavilla, on etsittävä kirjastoissa muualta kuin taidehistorian osastolta. Sen kaltaisten termien kuten esimerkiksi modernismi, kehitys ja suunnittelu tulkinnat, merkitykset ja vakiintuneet käyttötavat vaihtelevat tieteenalakohtaisesti ja vaativat siksi tutkijalta tarkkuutta.

Toiset haasteet ovat vähemmän käytännöllisiä ja liittyvät esimerkiksi siihen, kenen näkökulmasta tutkimus on tehty. Kehitysmaatutkimuksen runsaudesta huolimatta arkkitehtuurivientiä kehitysmaihin ei ole juuri tutkittu osana suomalaisen arkkitehtuurin tarinaa. ${ }^{9}$ Arkkitehtuurihistoriallisesta näkökulmasta avautuu kertomus siitä, kuinka arkkitehtien kasvavat ammattimaiset verkostot kietoutuivat kansainvälisten kehitysyhteistyön teorioiden ja instituutioiden ympärille, ja kuinka kasvava joukko suomalaisia arkkitehteja pääsi työskentelemään kansainvälisissä ympäristöissä osana suomalaista ulkopolitiikkaa. Suomen Tansaniassa toteuttamia kehitysyhteistyö-

$7 \quad$ Ks. kuitenkin Stephen Ward, "Transnational planners in a postcolonial world," in Crossing borders: International exchange and planning practices, eds. Patsy Healey \& Robert Upton (New York: Routledge, 2010), 47-72; Lukasz Stanek, Architecture in Global Socialism: Eastern Europe, West Africa, and the Middle East in the Cold War (Princeton: Princeton University Press, 2020); Carlos Nunes Silva, Urban planning in Sub-Saharan Africa: colonial and post-colonial planning cultures (New York: Routledge, 2015).

8 Kolonialismin ja Suomen suhteesta katso esimerkiksi Janne Lahti \& Rinna Kullaa, "Kolonialismin monikasvoisuus ja sen ymmärtäminen Suomen kontekstissa," Historiallinen aikakauskirja 4 (2020): 420-426.

9 Ks. kuitenkin Arne Nevanlinna: Oman elämän kintereillä (Helsinki: Siltala, 2014); Juhani Pallasmaa, Maailmassaolon taide: kirjoituksia arkkitehtuurista ja kuvataiteista (Helsinki: Painatuskeskus, 1993); Mikko Laakso \& Seppo Tamminen, Rakentajat maailmalla: vientirakentamisen vuosikymmenet (Helsinki: Suomen rakennusinsinöörien liitto, 2014). 
hankkeita 1960-luvulta 1980-luvun alkuun on kuitenkin tutkittu kehitysmaatutkimuksen piirissä hyvin kriittiseen sävyyn "ylhäältä alas" suuntautuvina, asiantuntijavetoisina modernisoimisprojekteina, joiden todelliset vaikutukset Tansanian kansalaisten kannalta jäivät vähäisiksi. ${ }^{10}$ Tieteellinen näkökulma vaikuttaa oleellisesti siihen, minkälaisen tarinan tutkimus kertoo tai ketä tutkimus palvelee.

Keskustelu taidehistorian ja kehitysmaatutkimuksen välisestä suhteesta tiivistyy siihen, miten tiedekenttä on Suomessa järjestäytynyt. Kehitysyhteistyö on helpompi mieltää osaksi arkkitehtuurin tai yhdyskuntasuunnittelun historiaa kuin taidehistoriaa. Kehitysmaakontekstissa ei kuitenkaan ole välttämättä mielekkäintä ajatella tutkivansa 'Arkkitehtuuria isolla A-kirjaimella'. Anja Kervanto Nevanlinnaa (1987) lainaten:

Jos ajattelemme "alallamme" tutkittavan Arkkitehtuuria isolla A-kirjaimella, hyvin vähän tutkimusta on julkaistu ei-läntisiin maihin liittyen, ja sekin vähä kaikkein poikkeuksellisimmista rakennuksista näiden maiden historiassa. Jos sen sijaan ajattelemme tutkivamme laajemmin kaupunki- ja kyläsuunnittelua, edullista asumista, tarkoituksenmukaista teknologiaa, vernakulaaria rakentamista jne., "alamme" tutkimusta on tehty merkittävissä määrin myös ei-länsimaisessa kontekstissa. Se, mitä länsimaalaiset valitsevat tutkia länsimaiden ulkopuolella vaikuttaa poikkeavan

10 Harri Porvali, Evaluation of the Development Cooperation Between the United Republic of Tanzania and Finland (Helsinki: Ministry for Foreign Affairs, Department for International Development Cooperation, 1995); Juhani Koponen, Finnish Aid to Tanzania: Still Afloat. niistä kysymyksistä, joita he tutkivat omissa kulttuureissaan. ${ }^{11}$

Taidehistorian tutkimuskysymysten ja näkökulmien sovittaminen kehitysyhteistyöhankkeiden tutkimiseen herättää kysymyksiä, jotka soveltuvat varmasti muihinkin taidehistoriallisiin tutkimuksiin, joissa kuva-aineisto ei ole tutkimuksen ensisijainen tai ainoa kohde, tai joissa kuva-analyysi ei ole ensisijainen metodi. Omassa tutkimuksessani kuva-aineisto muodostaa vain pienen osan aineistosta, joka muodostuu pääosin suunnitteluhankkeiden myötä muodostuneista projektiraporteista, hankehallintomateriaalista, kirjeenvaihdosta, poliittisista ohjelmapapereista, projektipiirustuksista ja ulkoministeriön kehitysyhteistyöosaston vuosiraporteista. Miten mielekästä on käyttää esimerkiksi kuva-analyysin keinoja materiaaliin, jota ei ole tarkoitettu käsitettäväksi kuvina? Missä mielessä esimerkiksi kartat tai erilaiset numeerisen datan visualisoinnit voivat olla kuvia? Mitä kulttuurin tutkimuksen näkökulmat voivat tuoda sellaisille ongelmakeskeisille aloille kuin kehitysmaatutkimus?

Taidehistoria on monipuolinen tieteenala, jota ei voi määritellä yksin kuvallisen aineiston tai kuva-analyysin keskeisyyden kautta. Kuitenkin alalla, kuten varmasti kaikilla aloilla, on omat melko vakiintuneet käsityksensä siitä, mitä taidehistoriassa on mielekästä tutkia ja mitä ei. Koloniaalisella ja jälkikoloniaalisella kaudella glo-

11 Suomennos kirjoittajan. Alkuperäinen muotoilu: "If we see 'our field' as Architecture with a big A [- - very little research has been published on the non-Western countries, and mostly on only very exceptional buildings from the country's history. If we, however, see 'our field' broadly to include studies on town and village planning, low-cost housing, appropriate building technology, vernacular buildings etc., research in our field has been practiced in some notable extent within the context of the non-Western world. What Westerners choose to study in non-Western countries seems to differ from the problems they study in their own cultures.' Anja Kervanto Nevanlinna, "Research as Continuous Education for Teachers," in Teaching for Development. NOFUA Conference in Helsinki 1987, toimittaneet Anja Kervanto Nevanlinna \& Antti Veltheim (Otaniemi: Helsinki University of Technology, 1987), 84. 
baaleissa verkostoissa tapahtunut kulttuurivaihto on vakiintunut osa kansainvälistä taidehistorian tutkimusta. Kehitysyhteistyöllä on tässä oleellinen osa, myös Suomen kaltaisessa maassa, jossa oman maan suhdetta kolonialismiin on tutkittu verrattain vähän aikaa. Siten poikkitieteellisten kysymysten kohtaaminen vaatii sekä yksittäiseltä tutkijalta että hänen edustamaltaan (pää)tieteenalalta joustavuutta ja rohkeutta kurottaa tieteenalarajojen välisiin suvanteisiin helposti katoavia tutkimusasetelmia kohti. Kysymys on myös yhä ajankohtaisempi. Esimerkiksi Suomen suhde kolonialismiin on jo rantautunut suomalaiseen historiantutkimukseen ja kotimaisen kirjallisuuden tutkimukseen. ${ }^{12}$ Saman keskustelun muodostuminen osaksi myös Suomen taidehistoriaa edellyttää kasvavaa avoimuutta sen suhteen minkälaisia aineistoja pidämme arvossa ja millä tavalla tutkimme niitä.

Essi Lamberg on väitöskirjatutkija Helsingin yliopistossa taidehistorian tieteenalalla. Hänen väitöskirjatutkimuksensa käsittelee suomalaisten arkkitehtien ja yhdyskuntasuunnittelijoiden työtä kehitysyhteistyön alalla 1960-luvulta 1980-luvulle.

12 Ks. esim. Janne Lahti \& Rinna Kullaa, "Kolonialismin monikasvoisuus ja sen ymmärtäminen Suomen kontekstissa"; Olli Löytty, Jäähyväiset kotimaiselle kirjallisuudelle (Helsinki: Teos, 2021). 